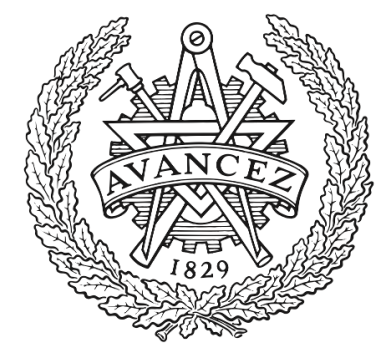

CHALMERS

UNIVERSITY OF TECHNOLOGY

\title{
A Strategy for the Sequential Recovery of Biomacromolecules from Red Macroalgae Porphyra umbilicalis Kützing
}

Downloaded from: https://research.chalmers.se, 2023-04-26 09:41 UTC

Citation for the original published paper (version of record):

Wahlström, N., Harrysson, H., Undeland, I. et al (2018). A Strategy for the Sequential Recovery of Biomacromolecules from Red Macroalgae Porphyra umbilicalis Kützing. Industrial \& Engineering Chemistry Research, 57(1): 42-53. http://dx.doi.org/10.1021/acs.iecr.7b03768

N.B. When citing this work, cite the original published paper. 


\title{
A Strategy for the Sequential Recovery of Biomacromolecules from Red Macroalgae Porphyra umbilicalis Kützing
}

\author{
Niklas Wahlström, ${ }^{\dagger}$ Hanna Harrysson, ${ }^{\ddagger}$ Ingrid Undeland, ${ }^{\ddagger}$ and Ulrica Edlund ${ }^{*}{ }^{\dagger} \odot$ \\ ${ }^{\dagger}$ Fiber and Polymer Technology, KTH Royal Institute of Technology, Teknikringen 56, SE-100 44 Stockholm, Sweden \\ ${ }^{\ddagger}$ Department of Biology and Biological Engineering, Food and Nutrition Science, Chalmers University of Technology, SE 412 \\ 96-Göteborg, Sweden
}

Supporting Information

\begin{abstract}
A nondestructive, multicomponent fractionation strategy has been developed to extract proteins and polysaccharides from the red macroalgae Porphyra umbilicalis collected along the west coast of Sweden and cultivated indoors under controlled conditions. First, a protein-rich fraction was extracted in an ice-cold alkaline solution. The overall protein content in Porphyra umbilicalis was estimated to be $30.6 \%$ of the dry weight, and out of that, $15.0 \%$ could be recovered. Water-soluble polysaccharides were then extracted from the insoluble residual fraction using sequential alkaline and acidic treatments at $90{ }^{\circ} \mathrm{C}$ for $4 \mathrm{~h}$. Spectroscopic and chromatographic analyses of the polysaccharide fractions show that high-molecular-weight

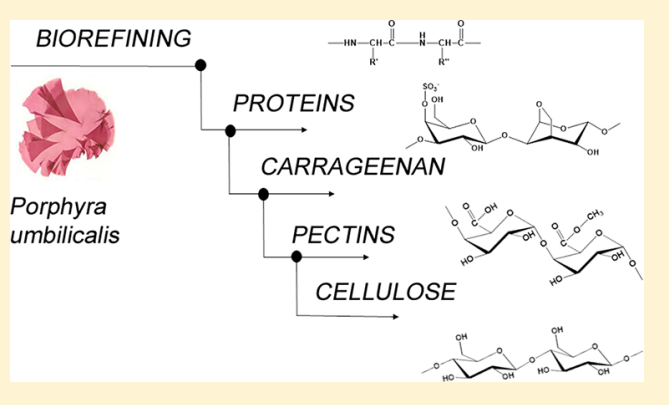
carrageenans were obtained from the alkaline extraction and a galactose-rich pectin substance was obtained from the acidic extraction. The insoluble fraction remaining after all extraction steps was rich in cellulose. An elemental analysis of Porphyra umbilicalis via scanning electron microscopy with energy-dispersive X-ray spectrometry (SEM-EDS) showed the presence of $\mathrm{C}, \mathrm{O}, \mathrm{Na}, \mathrm{Ca}, \mathrm{Mg}, \mathrm{Al}, \mathrm{Cl}$, and $\mathrm{S}$. However, no heavy metals or other toxic elements, such as $\mathrm{Pb}, \mathrm{Hg}$, and $\mathrm{As}$, were found.
\end{abstract}

\section{INTRODUCTION}

Macroalgae farming is a fast-growing area of aquaculture worldwide; however, so far, it has been largely undeveloped in Sweden, even though great potential exists for this industry there, because of Sweden's long coast line. Macroalgae farming offers several benefits, compared to land-based biomass production. It does not require irrigation, compete for valuable land area, or contribute to the negative effects associated with fertilizers. Therefore, macroalgae farming has been suggested as a possible way to mitigate global warming. ${ }^{1}$ Other advantages of macroalgae farming are that the biomass grows quickly and it does not contribute to coastal eutrophication. ${ }^{2}$ Macroalgae is a potential source for bioethanol production, and recent computational studies have shown that a biorefinery process can be designed such that biodiesel can be produced from alga with zero overall $\mathrm{CO}_{2}$ emission. ${ }^{3}$

Some species of macroalgae are important in food, medical, and nutritional applications, because of their high levels of polysaccharides, proteins, vitamins, and trace minerals. ${ }^{4}$ In particular, some of the water-soluble polysaccharides found in macroalgae often serve as thickening agents in the food industry, because of their excellent gelling abilities. ${ }^{4} \mathrm{~A}$ commercially valuable maricultured macroalgae is the red seaweed Porphyra (also known as Nori), which belongs to a family of red algae called Bangiaceae. In addition to its direct use in food and as a source of ingredients, it could be an attractive biomass base for biorefining. The main polysacchar- ides present in the cell walls of Porphyra are carrageenan, pectin, and cellulose.

Carrageenan is a family of water-soluble polysaccharides composed of repeating units of partially sulfated disaccharides. Carrageenan exists as different isomers, of which the three most common isomers are $\kappa$-, $l$-, and $\lambda$-carrageenan (Figure 1 ), where each monomer unit contains one, two, and three sulfate groups, respectively. ${ }^{5}$ The degree of sulfation of the carrageenan strongly affects its properties. The ability of carrageenans to form cross-linked gels in the presence of $\mathrm{K}^{+}$or $\mathrm{Ca}^{2+}$ ions is one reason why these biomacromolecules are gaining increasing attention $^{6}$ and why they have been investigated as potential hydrogel scaffolds in drug delivery and biomedical applications. ${ }^{7,8} \kappa$-Carrageenan forms firm and elastic cross-linked gels in aqueous solutions in the presence of $\mathrm{K}^{+}$ions and more brittle gels in the presence of $\mathrm{Ca}^{2+}$ ions; $l$-carrageenan forms soft gels in aqueous solution in the presence of $\mathrm{Ca}^{2+}$ ions. However, $\lambda$ carrageenan does not form any gels in the presence of metal ions.

The conventional and straightforward method for the extraction of carrageenan from red seaweed is the use of an alkaline aqueous solution $(\mathrm{pH} 8-10)$ at high temperature $(T=$ 80-95 ${ }^{\circ} \mathrm{C}$ ) for $2-4 \mathrm{~h}$. The dissolved carrageenan is

Received: September 11, 2017

Revised: November 18, 2017

Accepted: November 28, 2017

Published: November 28, 2017 


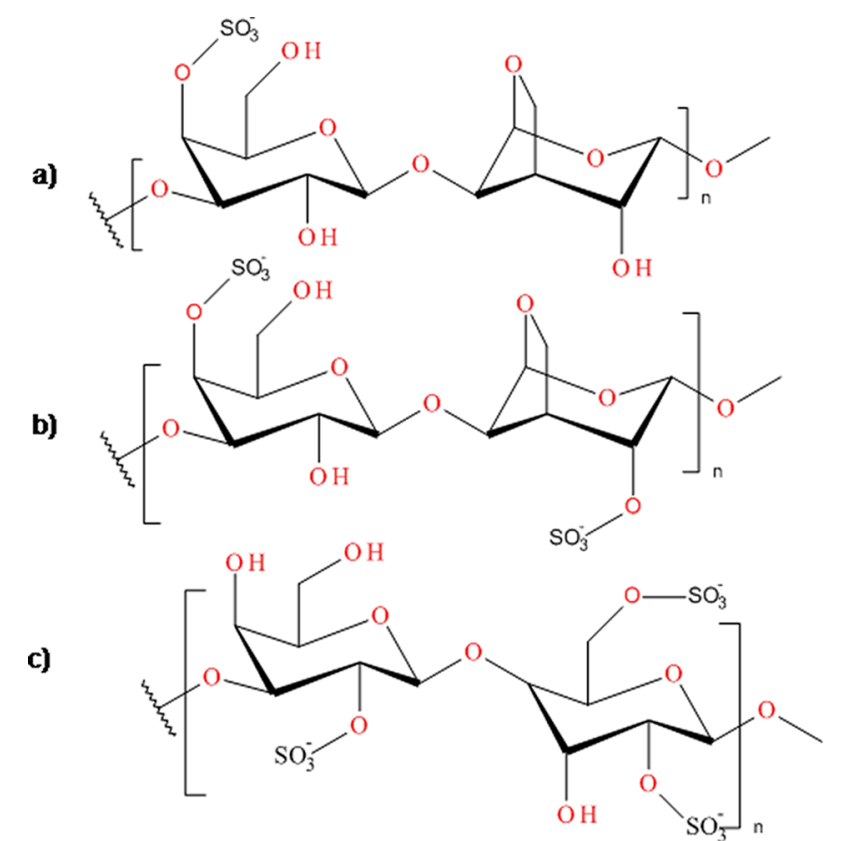

Figure 1. Representative repeating unit motifs of (a) $\kappa$, (b) $l$, and (c) $\lambda$-carrageenan.

precipitated by adding ethanol to the supernatant. ${ }^{6}$ However, another extraction method has also been suggested involving microwave-assisted extraction, which reduces the extraction time to $10-20 \mathrm{~min}$ and reduces the consumption of solvents and energy required for the extraction process, compared with extraction in an aqueous alkaline solution. ${ }^{7}$ It is worth mentioning that commercial and conventional extraction techniques, such as the above-mentioned procedures, are designed to isolate carrageenan but they disregard other valuable components (such as proteins and lipids). The insoluble fraction remaining after extracting carrageenan is usually discarded, and no attempt is made to isolate the other valuable components. Hence, more than half of this potentially valuable biomass is wasted, which is in direct contradiction to the rapidly emerging need to use nature's resources in a more efficient and sustainable way. From a biorefinery point of view, it is essential to develop and implement biomass treatment techniques that allow us to recover as much of the valuable components in the biomass as possible. Unlike a traditional "one-component" approach, such techniques would help mitigate greenhouse gas emissions and the accumulation of waste fractions from industrial production. ${ }^{10}$ Biorefinery processes are widely used to recover valuable components such as levulinic acid, succinic acid, and bioethanol from different types of biomasses. ${ }^{11,12}$ Developing and applying a biorefinery type of process to red seaweed is important to use the biomass more effectively and steering away from the current industrial approach to isolate only the carrageenan while discarding the rest of the biomass. So far, only little progress has been made toward developing sequential processes in the field of macromolecule extractions from seaweed biomass. Recently, a procedure for the recovery of proteins from brown seaweed (Saccharina latissima) was reported, and that procedure is built upon cold alkaline extraction, followed by isoelectric precipitation, often called $\mathrm{pH}$-shift processing. ${ }^{13}$ The method has since been adapted to red and green seaweed species. ${ }^{14}$ In addition, similar procedures have been reported for seaweed proteins that use ammonium sulfate in the protein precipitation step; however, these methods require a subsequent dialysis step to desalt the product. In all of these methods, as in traditional carrageenan extractions, a large portion of the biomass ends up in waste fractions. One such fraction is the non-alkali-soluble fraction that is removed during the first centrifugation step. We hypothesize that (i) this fraction contains a large amount of the cell wall-derived polysaccharides, which, in fact, decrease the extractability of the proteins, ${ }^{15,16}$ and (ii) this fraction could therefore be a promising substrate for, e.g., carrageenan extractions.

Based on this hypothesis, our aim is to develop a strategy for the multicomponent fractionation of biomacromolecules (foodgrade proteins and polysaccharides) from the red algae Porphyra umbilicalis collected along the west coast of Sweden to allow for a more-efficient use of the algal polymeric components. The goal is that each extraction step can be carried out without causing unwanted degradation of the other components; for example, proteins require cold conditions while polysaccharides are more heat-resistant. Unwanted modification or degradation of the proteins (e.g., denaturation or losses of essential amino acids) and polysaccharides (e.g., molecular weight reduction) may lead to losses in the technofunctional properties, nutritional value, and material properties. The exact polysaccharide composition of Porphyra umbilicalis is not fully established, so another objective of this study is to structurally map and characterize the different recovered polysaccharide fractions from this algal species. Regarding the fractions recovered, the protein contents and the isomeric composition of the carrageenan-, cellulose-, and the pectin-enriched extracts will be investigated.

\section{EXPERIMENTAL SECTION}

2.1. Materials. Porphyra umbilicalis were collected on November 22, 2015, from Inre Vattenholmen ( $58^{\circ} 52^{\prime} 37.4^{\prime \prime} \mathrm{N}$ $\left.11^{\circ} 6^{\prime} 52.1^{\prime \prime} \mathrm{E}\right)$ and brought back to the laboratory within $2 \mathrm{~h}$ of collection. Collected Porphyra umbilicalis tufts were rinsed several times in natural seawater to remove grazers and loose epiphytes. Tufts were then placed into cultivation tanks $(60 \mathrm{~L})$ and cultivated at a temperature of $10{ }^{\circ} \mathrm{C}$ in a neutral light cycle (12 h daylight, $12 \mathrm{~h}$ darkness) at a light intensity of $140 \mu \mathrm{E} \mathrm{m}^{-2}$ $\mathrm{s}^{-1}$. The light source was an OSRAM Lumilux Warm White 58 $\mathrm{W}$ bulb. The seaweeds continuously received filtered seawater that was passed through $1 \mu \mathrm{m}$ filters. No additional medium or chemicals were added to the water. The natural seawater used in the flow-through system was pumped in from outside the bay. Thus, the salinity may have fluctuated somewhat, depending on the freshwater coming in from the coast. No salinity measurements were performed, but the salinity in this region is typically ca. 25 ppt.

Sodium carbonate ( $\geq 99.5 \%$ purity), sodium hydroxide ( $\geq 99.98 \%$ purity), potassium chloride ( $\mathrm{KCl}$ ), calcium chloride $\left(\mathrm{CaCl}_{2}\right), 37 \%$ hydrochloric acid, ethanol (96\% purity), reference carrageenan (type II, which contains mostly $\kappa$ carrageenan and a minor amount of $\lambda$-carrageenan, $\mathrm{Mw}=$ $950000 \mathrm{Dg} / \mathrm{mol})$, methanol ( $\geq 99.98 \%$ purity), acetyl chloride ( $\geq 99 \%$ purity), pyridine ( $\geq 98 \%$ purity), trifluoroacetic acid (99.5\% purity), toluene ( $\geq 99.99 \%$ purity), deuterium oxide ( $\geq 99.8 \%$ purity), L- $(+)$-arabinose ( $\geq 99 \%$ purity), D- $(+)$-glucose ( $\geq 99 \%$ purity), D- $(+)$-mannose $(\geq 99 \%$ purity), D- $(+)$-galactose ( $\geq 99 \%$ purity), D- $(+)$-xylose ( $\geq 99 \%$ purity), D- $(+)$ rhamnose ( $\geq 99 \%$ purity), D- $(+)$-glucuronic acid ( $\geq 98 \%$ purity), $\mathrm{D}-(+)$ galacturonic acid, and $\alpha$-cellulose (from spruce wood) were all 


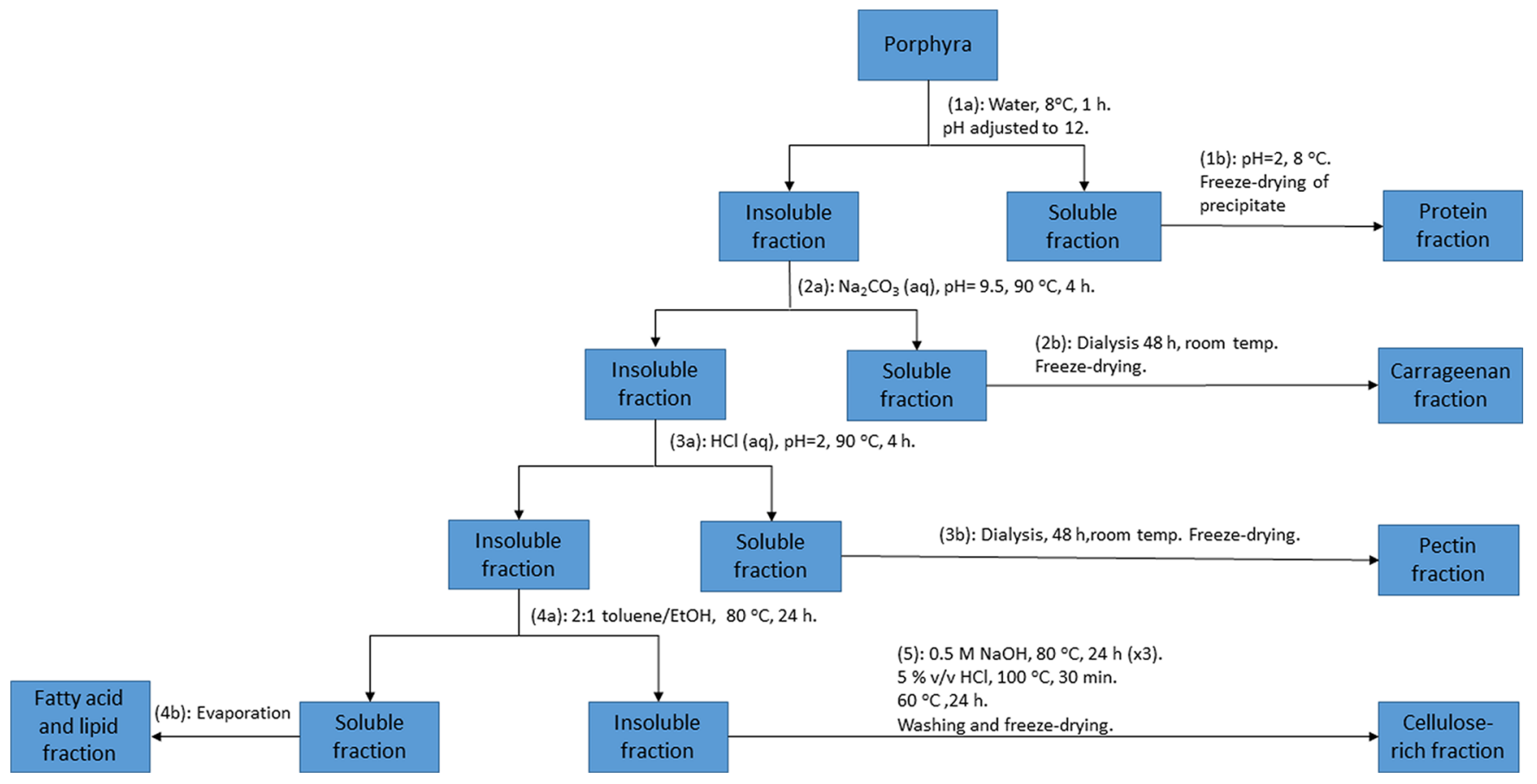

Figure 2. Schematic illustration of the sequential fractionation protocol for protein and polysaccharides recovery from Porphyra umbilicalis. The numbered labels (1) $-(5)$ correspond to the individual isolation steps.

purchased from Sigma-Aldrich. Sulfuric acid (72\%) was purchased from Labservice $A B$, Sweden, and lemon pectin $\geq 90 \% \quad(\geq 74 \%$ galacturonic acid, with trace amounts of arabinose, glucose, galactose, rhamnose, mannose, xylose, and glucuronic acid; $\mathrm{Mw}=100000 \mathrm{~g} / \mathrm{mol}$ ) was purchased from Alfa Aesar. Hydrochloric acid (37\%) for protein extraction was purchased from Acros (Gothenburg, Sweden). Dialysis membranes were purchased from Spectrum Laboratories, Inc. $(\mathrm{MWCO}=1.0 \mathrm{~kg} / \mathrm{mol}, 6.4 \mathrm{~mL} / \mathrm{cm})$.

2.2. Fractionation of Biomacromolecules. The fractionation of the macromolecular components in Porphyra umbilicalis was carried out as outlined in the schematic in Figure 2. The numbered labels (1)-(5) correspond to the individual extraction steps that are further explained in Sections 2.2.1-2.2.5.

2.2.1. Step (1): Extraction of Proteins. Protein from Porphyra was extracted as described by Harrysson et al. ${ }^{14}$ In short, dry-milled Porphyra was homogenized in distilled water in a 1:43.6 ratio, which corresponded to a 1:6 ratio, based on the algal wet weight, using a Turrax IKA T18 basic for 2 min at $18000 / \mathrm{min}$, followed by milling with beads using a Retsch MM 400 at a speed of $1 / 30 \mathrm{~s}$ for $2 \mathrm{~min}$. Finally, this process was followed by stirring for $1 \mathrm{~h}$ at $8{ }^{\circ} \mathrm{C}$. While keeping the homogenate on ice, the $\mathrm{pH}$ was adjusted to 12 with $1 \mathrm{M} \mathrm{NaOH}$ and the mixture was centrifuged at $8000 \mathrm{~g}$ for $10 \mathrm{~min}\left(4^{\circ} \mathrm{C}\right)$. The supernatant was decanted and kept on ice while the $\mathrm{pH}$ was adjusted to 2 with $1 \mathrm{M} \mathrm{HCl}$. The sediment (insoluble fraction) was collected, frozen at $-80{ }^{\circ} \mathrm{C}$, and then freeze-dried for the subsequent extraction of carrageenan (see Section 2.2.2). The supernatant was frozen overnight at $-20{ }^{\circ} \mathrm{C}$, then thawed and centrifuged at $8000 \mathrm{~g}$ for $10 \mathrm{~min}\left(4^{\circ} \mathrm{C}\right)$, The pellet (protein fraction) was collected, freeze-dried and stored at -80 ${ }^{\circ} \mathrm{C}$ until further analysis. The extraction was done in duplicate. The protein yield was calculated according to the following formula:

$$
\begin{aligned}
& \text { protein yield }(\%) \\
& =\frac{(\text { total protein in the isolate }) \times(\text { amount of isolate achieved })}{(\text { total protein in the crude seaweed }) \times(\text { amount of seaweed })} \times 100
\end{aligned}
$$

and the deviation was calculated as

$$
\text { deviation }=\frac{(\text { maximum yield })-(\text { minimum yield })}{2}
$$

The weight yield was calculated as the mass of the freezedried fractions divided by the mass of the dried starting algae material.

To determine whether there were significant differences between data from the crude seaweed and the protein-rich fraction, a $t$-test was carried out using SPSS (IBM Corp., Armonk, NY, USA). The equality of variances between the two groups was calculated using Levene's test.

2.2.2. Step (2): Extraction of Carrageenan. Carrageenan was extracted by the method suggested by Hilliou et al., with some modifications. A freeze-dried subsample $(2 \mathrm{~g})$ of the insoluble fraction from step (1) was stirred in $1.0 \mathrm{M} \mathrm{Na}_{2} \mathrm{CO}_{3}$ at room temperature for $24 \mathrm{~h}$. The sample was washed several times with water and suspended in $200 \mathrm{~mL}$ of $\mathrm{Na}_{2} \mathrm{CO}_{3}$ solution ( $\mathrm{pH} 9.5$ ). The mixture was stirred at $90{ }^{\circ} \mathrm{C}$ for $4 \mathrm{~h}$ (Figure 2, step (2a)). After cooling to room temperature, the mixture was centrifuged at $4000 \mathrm{rpm}$ for $10 \mathrm{~min}$ and the supernatant was collected, dialyzed for $48 \mathrm{~h}$, and then freeze-dried (Figure 2, step $(2 \mathrm{~b})$ ). In one trial, an alternative workup procedure was used in which the supernatant was concentrated by evaporation and then precipitated in an excess of cold ethanol. The precipitate was recovered by centrifugation and dried. The insoluble fraction from the carrageenan extraction was kept for further extractions.

2.2.3. Step (3): Extraction of Pectin. The insoluble fraction remaining after the carrageenan extraction in step (2) was washed several times with water in order to remove any traces from the previous extraction. The washed sample was then 
suspended in $200 \mathrm{~mL}$ of $0.01 \mathrm{M} \mathrm{HCl}(\mathrm{pH} 2)$ and heated to 90 ${ }^{\circ} \mathrm{C}$ for $4 \mathrm{~h}$ (Figure 2, step (3a)). After cooling to room temperature, the mixture was centrifuged at $4000 \mathrm{rpm}$ for 10 $\mathrm{min}$ and the supernatant was collected and freeze-dried (Figure 2 , step (3b)). The insoluble fraction was kept for further extractions.

2.2.4. Step (4): Removal of Lipids, Fatty Acids, and Other Water-Insoluble Components. Fatty acids, lipids, and other water-insoluble components were removed from the insoluble fraction in step (4a) to produce the final cellulose-rich fraction. To make the process comparably more environmentally friendly, a method using toluene and ethanol ${ }^{11}$ was chosen in favor of the more traditional method by Lee et al., which uses chloroform and methanol. ${ }^{17}$ The insoluble fraction remaining from step (3) was stirred in $200 \mathrm{~mL}$ of a 2:1 toluene/ethanol mixture for $24 \mathrm{~h}$ at $80^{\circ} \mathrm{C}$ (Figure 2, step (4a)). After cooling to room temperature, the mixture was centrifuged at $4000 \mathrm{rpm}$ for $10 \mathrm{~min}$ and the supernatant was removed (Figure 2, step (4b)). The insoluble fraction was kept for further isolation of the cellulose. No further analysis of the fatty acids and lipids in the supernatant was performed in this study.

2.2.5. Step (5): Isolation of the Cellulose-Rich Fraction. A modified version of the method suggested by Siddhanta et al. ${ }^{18}$ was used in an attempt to obtain a cellulose-rich insoluble fraction. The insoluble fraction that remained from step (4a) was suspended in $0.5 \mathrm{M} \mathrm{NaOH}$ and heated to $80{ }^{\circ} \mathrm{C}$ for $24 \mathrm{~h}$ (Figure 2, step (5)). The mixture was centrifuged at $4000 \mathrm{rpm}$ for $10 \mathrm{~min}$. The supernatant was removed and the insoluble fraction was washed several times with water until the washing water reached a neutral $\mathrm{pH}$. The procedure was repeated twice. After washing, the insoluble fraction was suspended in $5 \% \mathrm{HCl}$ and heated to boiling for $30 \mathrm{~min}$. The resulting slurry was then stirred at $60{ }^{\circ} \mathrm{C}$ for $24 \mathrm{~h}$. The sample was centrifuged at 4000 $\mathrm{rpm}$ for $10 \mathrm{~min}$ and the insoluble fraction was washed several times with water to remove excess acid. The final insoluble fraction was freeze-dried for further characterization.

2.3. Gel Formation from the Carrageenan Fraction. The carrageenan-rich fraction recovered by precipitation with ethanol was used to prepare gels. A commercial carrageenan (a high-purified $\kappa$-carrageenan) was used as a reference. Carrageenan samples were first dissolved in deionized water at a concentration of $1 \%(\mathrm{w} / \mathrm{w})$; however, the concentration of the commercial carrageenan was $0.8 \%(\mathrm{w} / \mathrm{w})$, because of its high viscosity. To each sample, $0.5 \mathrm{~mL}$ of either a $\mathrm{CaCl}_{2}$ or a $\mathrm{KCl}$ solution ( $1 \% \mathrm{w} / \mathrm{w}$ in water) was added under stirring. The samples were heated to $80{ }^{\circ} \mathrm{C}$ and then allowed to cool to room temperature.

2.4. Characterization of Crude Biomass and Fractions. 2.4.1. Nuclear Magnetic Resonance Spectroscopy ( ${ }^{1} H$ NMR). The carrageenan and pectin fractions (i.e., fractions recovered in steps (2) and (3)) were analyzed by ${ }^{1} \mathrm{H}$ NMR. Freeze-dried samples $\left(25 \mathrm{mg}\right.$ ) were dissolved in $1.0 \mathrm{~mL}$ of $\mathrm{D}_{2} \mathrm{O}$, and $\mathrm{NMR}$ spectra were recorded on a Bruker DMX-500 NMR spectrometer at $500 \mathrm{MHz}$. The spectra were calculated as an average of 128 scans, and the data were analyzed using MestReNova software.

2.4.2. Fourier Transform Infrared (FTIR) Spectroscopy. FTIR spectra of dried Porphyra umbilicalis and the dried fractions recovered in steps (2), (3), and (5) were recorded between $4000 \mathrm{~cm}^{-1}$ and $600 \mathrm{~cm}^{-1}$ at room temperature, using a PerkinElmer Spectrum 2000 FTIR with an attenuated total reflectance crystal accessory (ATR Golden Gate). Corrections were made for atmospheric water and carbon dioxide in all of the measurements, and the spectra were calculated as an average of 64 scans. The data were analyzed using PerkinElmer Spectrum software.

2.4.3. Size-Exclusion Chromatography (SEC). The molecular weights and dispersities of the extracted water-soluble polysaccharides (fractions recovered in steps (2b) and (3b)) were estimated using a Dionex Ultimate-3000 HPLC system (Dionex Sunnyvale, CA, USA). Dried samples $(20 \mathrm{mg}$ ) were completely dissolved in $10 \mathrm{~mL}$ of $10 \mathrm{mM} \mathrm{NaOH}$. Before injection, the samples were filtered through $0.20 \mu \mathrm{m}$ polytetrafluoroethylene (PTFE) filters. The HPLC system was equipped with a WPS-3000SL autosampler, an LPG3400SD gradient pump, three PSS Suprema columns with pore sizes of 30,1000 , and $1000 \AA$ in series $(300 \mathrm{~mm} \times 8 \mathrm{~mm}, 10$ $\mu \mathrm{m}$ particle size $)$ together with a guard column $(50 \mathrm{~mm} \times 8$ $\mathrm{mm}, 10 \mu \mathrm{m}$ particle size) and a Waters-410 Refractive Index Detector (Wafers, Milford, CA, USA). The mobile phase was $10 \mathrm{mM} \mathrm{NaOH}$ and the temperature was kept at $40{ }^{\circ} \mathrm{C}$. Pullulan samples with molecular weights ranging from $342 \mathrm{~g} / \mathrm{mol}$ to $708000 \mathrm{~g} / \mathrm{mol}$ were used as reference samples.

2.4.4. High-Performance Anion Exchange Chromatography with Pulsed Amperiometric Detection (HPAEC-PAD). The composition of the monosaccharides and uronic acids in the Porphyra umbilicalis biomass and in the polysaccharide fractions recovered in steps (2), (3), and (5) were assessed using high-performance anion exchange chromatography with pulsed amperiometric detection (HPAEC-PAD). Acid hydrolysis of Porphyra and the insoluble fraction to hydrolyze the polysaccharides into monosaccharides was performed by adding $0.8 \mathrm{~mL}$ of $72 \% \mathrm{H}_{2} \mathrm{SO}_{4}$ to each $25 \mathrm{mg}$ sample. The samples were left on a shaking board at room temperature for $90 \mathrm{~min}$. Thereafter, $9.2 \mathrm{~mL}$ of water was added to obtain a final volume of $10 \mathrm{~mL}$. The samples were placed on a shaking board and left for $70.5 \mathrm{~h}$ at $80^{\circ} \mathrm{C}$. One of the main components in pectin is galacturonic acid. Previous studies have shown that acid hydrolysis by a strong acid such as sulfuric acid causes partial degradation of galacturonic acid. ${ }^{19}$ Therefore, an alternative mild hydrolysis method was used in combination with methanolysis for the pectin fraction. A dried pectin sample $(1.0 \mathrm{mg})$ was placed in an oven-dried Pyrex tube and $1 \mathrm{~mL}$ of 2 $\mathrm{M} \mathrm{HCl}$ solution in methanol was added to the tube. The tube was sealed and heated to $100{ }^{\circ} \mathrm{C}$ for $5 \mathrm{~h}$ in a heating block. The solution was then neutralized by adding $200 \mu \mathrm{L}$ of pyridine to the reaction tube. The sample was cooled to room temperature and the solvent was evaporated under flowing $\mathrm{N}_{2}$ gas. Hydrolysis was then performed by adding $1 \mathrm{~mL}$ of $2 \mathrm{M}$ trifluoroacetic acid (TFA) to the dried sample, and the solution was then heated to $120{ }^{\circ} \mathrm{C}$ for $1 \mathrm{~h}$ in a heating block, followed by cooling to room temperature. All samples were diluted by a factor of 10 with distilled water, and the composition of carbohydrates and uronic acids was determined using a highperformance anion exchange chromatograph equipped with a pulsed amperiometric detector (HPAEC-PAD, ICS-3000 Dionex, Sunnyvale, CA, USA). The column was a CarboPac PA1 $(4 \mathrm{~mm} \times 250 \mathrm{~mm})$ column, and Milli-Q water, $0.26 \mathrm{M}$ $\mathrm{NaOH}$, and $0.17 \mathrm{M} \mathrm{NaOAc}$ were used as the mobile phase. A mixture of arabinose, rhamnose, galactose, glucose, xylose, mannose, galacturonic acid, and glucuronic acid was used as the reference sample. The data were processed and analyzed using Chromelon 7.1.

2.4.5. Thermogravimetric Analysis (TGA). The moisture, char, and ash content of the Porphyra umbilicalis biomass and the dried fractions recovered in steps (1), (2), (3), and (5) 
were estimated using a Mettler-Toledo TGA/DSC system. A quantity of $\sim 4 \mathrm{mg}$ of each sample was heated from $40{ }^{\circ} \mathrm{C}$ to $800{ }^{\circ} \mathrm{C}$ at a heating rate of $10^{\circ} \mathrm{C} / \mathrm{min}$ under an $\mathrm{N}_{2}$ atmosphere. The flow rate was set to $50 \mathrm{~mL} / \mathrm{min}$. After being heated to 800 ${ }^{\circ} \mathrm{C}, \mathrm{O}_{2}$ was introduced instead of $\mathrm{N}_{2}$ and the temperature was kept at $800{ }^{\circ} \mathrm{C}$ for $15 \mathrm{~min}$. The moisture content was calculated as the weight lost by the samples between $40^{\circ} \mathrm{C}$ and $110^{\circ} \mathrm{C}$. The char content was calculated as the weight remaining after the samples were heated to $800{ }^{\circ} \mathrm{C}$ in $\mathrm{N}_{2}$, and the ash content was calculated as the mass remaining after the completed program.

2.4.6. Scanning Electron Microscopy (SEM) and Elemental Analysis via Energy-Dispersive Spectroscopy (EDS). The surfaces and internal morphologies of the algal parts before grinding, and during different stages of extraction, were observed by ultrahigh-resolution field emission scanning electron microscopy (FE-SEM), using a Hitachi S-4800 system. The samples were air-dried at room temperature overnight and then attached to the sample supports, using double-sided adhesive carbon tape, and sputter-coated with an 8-nm-thick $\mathrm{Pt} / \mathrm{Pd}$ layer, using a Cressington 208HR under an inert atmosphere. The elemental composition of selected areas was assessed via SEM-EDS (energy-dispersive spectrum) using an $\mathrm{X}-\mathrm{Max}^{\mathrm{N}}$ from Oxford Instruments. Aztec 3.0 software was used for imaging SEM-EDS data.

2.4.7. Analysis of the Total Protein Content. The total nitrogen content in the protein extract was analyzed by a LECO Trumac nitrogen analyzer (USA). A conversion factor of 5 was used to convert total nitrogen to protein. ${ }^{20}$

\section{RESULTS AND DISCUSSION}

Consistent with the biorefinery concept, we developed a multicomponent fractionation strategy that allows for the recovery of proteins and polysaccharides from Porphyra, which is in contrast with the conventional methods that target only the carrageenan component or proteins. Chemical analyses of the polysaccharide fractions were also carried out to obtain a deeper understanding of the exact polysaccharide composition of Porphyra umbilicalis grown along the west coast of Sweden.

3.1. Extraction Yields for Proteins and Polysaccharides. The developed fractionation protocol yielded four individual macromolecular fractions (Figure 2, steps (1b), (2b), (3b), and (5)) and the weight yields of the proteins and polysaccharide-rich fractions are given in Table 1 . The weight yields are calculated as the mass of the freeze-dried fractions divided by the mass of the dried starting algae material. In addition, we calculated the specific protein yield in the fraction recovered from step (1) (see Section 2.2.1) to $15 \% \pm 4.8 \%$. The specific yield of the Porphyra protein obtained in the

Table 1. Extraction Weight Yields for Proteins and Polysaccharides Enriched Fractions Extracted from Porphyra umbilicalis $^{a}$

$\begin{array}{lc}\text { compound } & \text { weight yield (\%) } \\ \text { protein-rich fraction } & 7.5 \pm 2.4 \\ \text { carrageenan-rich fraction } & 19.9 \pm 3.9 \\ \text { pectin-rich fraction } & 19.2 \pm 4.3 \\ \text { cellulose-rich fraction } & 1.2^{b}\end{array}$

${ }^{a}$ The values are given as the mass of the freeze-dried fractions divided by the mass of the dried starting algae material. ${ }^{b}$ No standard deviation is given because the value is based on a single extraction. fraction recovered from step (1) is in the same range as the value obtained when the $\mathrm{pH}$-shift process was applied to Saccharina latissimi (16.01\%). ${ }^{13}$ However, the latter yield was calculated based on protein measurements of the supernatants obtained throughout the $\mathrm{pH}$-shift process using the spectrophotometric Lowry analysis principle and not on analysis of total nitrogen in final extracts. Using a similar analysis and calculation procedure as that used by Vilg et al. ${ }^{13}$ in the present study resulted in a protein yield of $26.1 \%$ for Porphyra umbilicalis. This higher yield could have been due in part to the freezing step during the isoelectric precipitation. Precipitation is when most seaweed proteins are lost; the alkaline solubilization step recovers up to $59.6 \%$ of the proteins. However, it was recently shown that freeze-thaw cycles increased the precipitation yield by $8.5 \% .{ }^{14}$ Our yield here was lower than protein yields $(46.3 \%$ and $45.4 \%)$ reported from other red seaweeds (Hypnea charoides and Hypnea japonica, respectively) using alkali or solubilization in combination with 2mercaptoethanol, followed by ammonium sulfate precipitation. ${ }^{21}$ However, using 2-mercaptoethanol in the solubilization step prevents the protein concentrates from being food-grade. Carrageenan can be recovered as a solid by adding ethanol to the supernatant after conventional alkaline extraction. ${ }^{6}$ Here, however, after adding ethanol to the supernatant in a $2: 1$ volume ratio after extraction of the carrageenan, a suspension was obtained, rather than a precipitate. This may have been due to the low concentration of the carrageenan in the supernatant, which may have required a larger volume of ethanol to fully recover the carrageenan as a solid. For this reason, the carrageenan was recovered by freeze-drying instead of precipitation, to limit the loss of product. The same behavior was observed after the extraction of pectin. No solid product was recovered after the addition of ethanol, which indicated a very low concentration of pectin. Therefore, the pectin fraction was also recovered by freeze-drying. As seen in Table 1 , only $1.2 \%(\mathrm{w} / \mathrm{w})$ of the initial material remained as an insoluble fraction after all extraction steps. However, product loss occurred during the last freeze-drying step due to difficulties in retrieving the samples from the round flask; hence, this value is less reliable than the values for the other fractions.

The SEM analysis revealed the topography of the Porphyra umbilicalis blades before grinding and the effect of progressive fractionation (Figure 3). Before treatment, the dried blades had flat structures without holes or pores on their surfaces. After grinding and freeze-drying, and as the extraction proceeded, the surface becomes progressively rougher, more cavitated, and more eroded, and eventually it left behind an insoluble fibrous scaffold.

3.2. Analysis of the Composition of Porphyra umbilicalis before and after Fractionation. The FTIR spectrum of Porphyra umbilicalis shows many of the characteristic peaks for polysaccharides (Figure 4, left). A list of the identified peaks and peak designations is available in Table S2 in the Supporting Information. The broad band at 3500-3200 $\mathrm{cm}^{-1}$ corresponds to the $\mathrm{O}-\mathrm{H}$ stretching of the hydroxyl groups, and the bands from $3000 \mathrm{~cm}^{-1}$ to $2800 \mathrm{~cm}^{-1}$ correspond to $\mathrm{C}-\mathrm{H}$ stretching. ${ }^{22}$ The band located between $1630 \mathrm{~cm}^{-1}$ and $1600 \mathrm{~cm}^{-1}$ corresponds to the $\mathrm{O}-\mathrm{H}$ stretching of bonded water. ${ }^{16}$ The sharp peaks at $1374 \mathrm{~cm}^{-1}$ and 1032 $\mathrm{cm}^{-1}$ correspond to $\mathrm{C}-\mathrm{H}$ bending and $\mathrm{C}-\mathrm{O}-\mathrm{C}$ linkages, respectively. ${ }^{16}$ The small peak at $898 \mathrm{~cm}^{-1}$ is characteristic of the $\beta$-glycoside bond, which confirms that sugar units linked together in the polysaccharide structures are present in the 


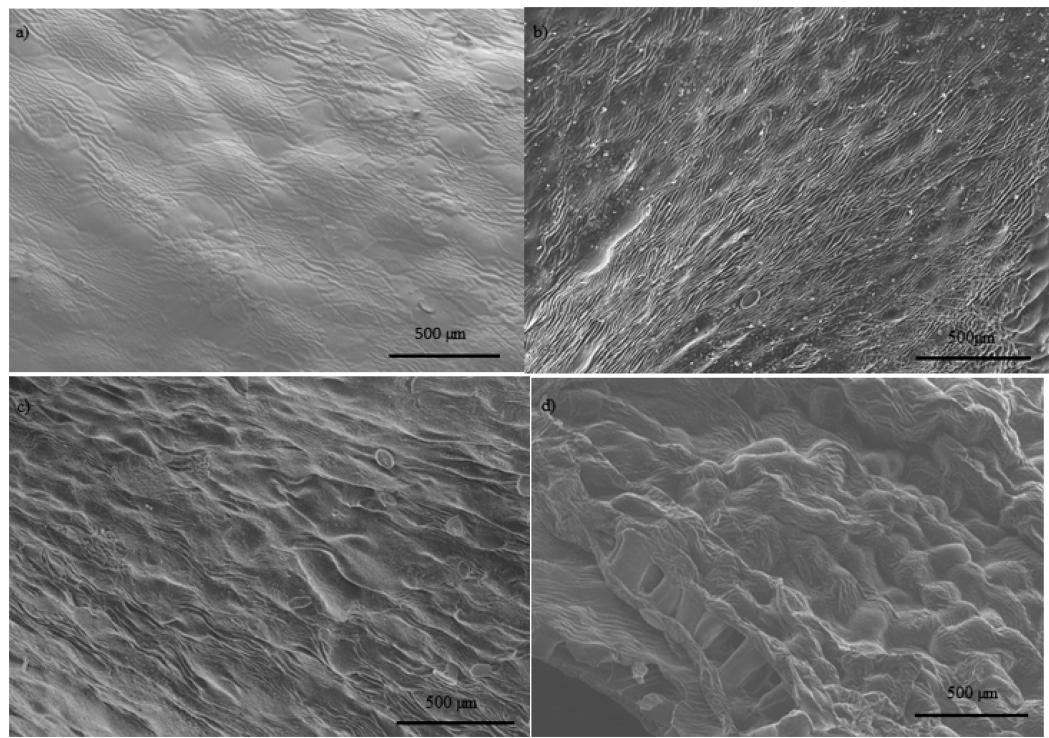

Figure 3. SEM images at 500× magnification of algal leaves of Porphyra umbilicalis at different stages of fractionation: (a) before grinding and fractionation, (b) after treatment in $1.0 \mathrm{M} \mathrm{Na}_{2} \mathrm{CO}_{3}$ for $24 \mathrm{~h}$ at room temperature (step (2)), (c) after treatment in $\mathrm{Na}_{2} \mathrm{CO}_{3}$ and the extraction of carrageenan (step (2b)), and (d) after the extraction of pectin (step (3)).
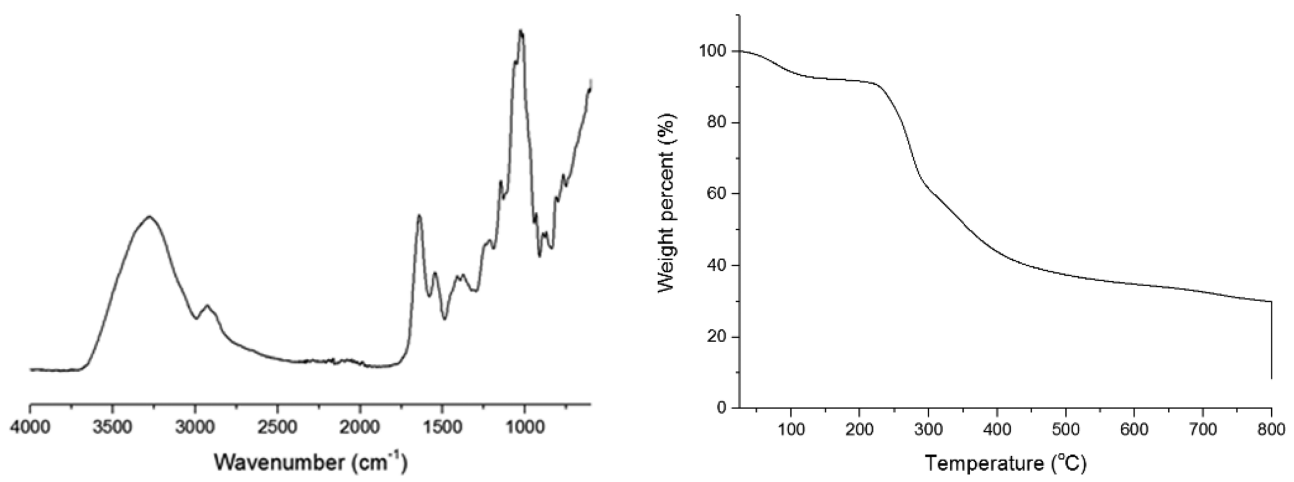

Figure 4. FTIR spectrum (left) and TGA curve (right) of Porphyra umbilicalis before fractionation.

Table 2. Char and Ash Contents in $\%(w / w)$ in Freeze-Dried Porphyra umbilicalis before Fractionation and in Recovered Samples after the Fractionation Steps ${ }^{a}$

\begin{tabular}{lcccc} 
& Porphyra umbilicalis & protein-rich fraction & carrageenan-rich fraction & pectin-rich fraction \\
\hline char (\% dry weight) & $31.9 \pm 0.3$ & $34.3 \pm 4.2$ & $29.2 \pm 0.8$ & $40.6 \pm 0.8$ \\
ash (\% dry weight) & $9.1 \pm 0.3$ & $10.7 \pm 2.1$ & $12.1 \pm 2.2$ & $7.7 \pm 1.6$
\end{tabular}

${ }^{a}$ The values were calculated as described in Section 2.4.6. The ash and char data are expressed as percentages (on a dry weight basis). The data are given as mean values of two replicates.

biomass. Thus, as indicated by the FTIR results, polysaccharides are the main components in Porphyra umbilicalis. The sharp peak at $1544 \mathrm{~cm}^{-1}$ stems from $\mathrm{N}-\mathrm{H}$ bending in the amines, which indicates the presence of proteins. ${ }^{16}$

The moisture, char, and ash content in freeze-dried Porphyra umbilicalis were calculated from the TGA thermogram (see Table 2 and Figure 4, right). The differential weight loss data versus temperature, as measured with TGA, is available in Figure S2 in the Supporting Information. The ash content $(8.5 \%)$ is lower than other values previously reported for red seaweed. $^{23,24}$

The total protein content, calculated as the total nitrogen in crude Porphyra umbilicalis, was $30.6 \% \pm 0.7 \%$ (dry weight), which is in the same range as previously reported values for the protein contents in Porphyra species $(22.7 \%-42.3 \%){ }^{25,26}$
The composition of the freeze-dried Porphyra umbilicalis biomass was further assessed using SEM-EDS to map the elemental composition (Table 3) and by HPAEC-PAD to reveal the carbohydrate composition (Table 4). As expected, the most common elements in Porphyra are oxygen and carbon, which is consistent with its high content of organic molecules, such as polysaccharides, proteins, and fatty acids. Sulfur $(S)$ is indicative of the sulfate groups in carrageenans and possibly also sulfur-containing amino acids (such as cysteine and/or methionine) in the proteins; however, those amino acids together only represent $1.7 \%$ of the total amino acids in crude Porphyra. ${ }^{14}$ It is important to note that the instrument we used is not equipped to analyze light elements (atom number <10) and the weight percentage values given for the typical elements in organic matter, such as oxygen, nitrogen, and carbon, are 
Table 3. Elemental Composition (in \% as determined by SEM-EDS) of Porphyra umbilicalis before Fractionation, and in Recovered Samples after Different Fractionation Steps ${ }^{a}$

$\begin{array}{ccccc}\text { element } & \begin{array}{c}\text { Porphyra umbilicalis } \\ \text { before fractionation }\end{array} & \begin{array}{c}\text { carrageenan- } \\ \text { rich fraction }\end{array} & \begin{array}{c}\text { pectin-rich } \\ \text { fraction }\end{array} & \begin{array}{c}\text { cellulose- } \\ \text { rich fraction }\end{array} \\ \mathrm{C} & 34.3 \pm 10 & 56.3 \pm 1.4 & 59.3 \pm 0.4 & 57.7 \pm 7.7 \\ \mathrm{O} & 36.6 \pm 1.1 & 23.2 \pm 7.3 & 25.0 \pm 1.6 & 34.4 \pm 4.2 \\ \mathrm{Na} & 17.4 \pm 8.4 & 3.6 \pm 1.3 & 3.1 \pm 0.1 & b \\ \mathrm{Mg} & 1.1 \pm 1.6 & 0.5 \pm 0.7 & 1.5 \pm 2.1 & b \\ \mathrm{Al} & 0.4 \pm 0.1 & 0.7 \pm 0.5 & b & b \\ \mathrm{~S} & 2.5 \pm 2.0 & 5.7 \pm 3.4 & b & b \\ \mathrm{Cl} & 7.6 \pm 0.3 & 10.1 \pm 7.0 & 11.1 \pm 0.2 & 1.1 \pm 0.1 \\ \mathrm{Ca} & 0.2 \pm 0.3 & 0.2 \pm 0.2 & b & 6.5 \pm 3.0\end{array}$

${ }^{a}$ The data are given as the mean values of two replicates. ${ }^{b}$ Value is below the detection limit.

highly approximate. Hydrogen cannot be detected at all with this technique and no nitrogen was detected, although Porphyra umbilicalis biomass clearly contains proteins. The results are more informative for heavier elements. Approximately $4.5 \mathrm{wt} \%$ sodium ( $\mathrm{Na}$ ) was found, and this result was likely due to sodium acting as the counterion to carrageenan. $\mathrm{Al}, \mathrm{Mg}, \mathrm{Cl}$, and Ca were also found, and their presence may be due to the composition of the seawater in which the algae were collected. These trace elements also contributed to an ash content of $\sim 8.5 \%$ (see Table 2). Importantly, no heavy metals or other toxic elements, such as $\mathrm{Pb}, \mathrm{Hg}, \mathrm{Pb}$, and $\mathrm{As}$, were detected.

Galactose appears to be the most common monosaccharide in Porphyra umbilicalis, which indicates the presence of carrageenan and possibly other galactans. The other monosaccharides indicate the presence of other polysaccharides such as cellulose and pectin. No glucuronic acid or galacturonic acid were detected in the Porphyra sample. The main reason for this behavior is that conventional harsh acid hydrolysis conditions were used in the pretreatment before HPAEC-PAD analysis, which resulted in total degradation of the uronic acids. HPAEC-PAD analysis allows only for quantification of the monosaccharide building blocks and does not reveal from which polysaccharide the monosaccharides originate. For this reason, the precise amount of the various polysaccharides cannot be determined individually and only a gross carbohydrate amount is known. Therefore, a detailed mass balance is difficult to make. An overall mass balance, based on the total carbohydrate content, is shown in Table S1 in the Supporting Information.

3.3. Specific Analysis of the Protein-Rich Fraction. The protein-rich fraction, which was the first fraction separated in the sequential processing, contained $57.2 \% \pm 3.8 \%$ protein on a dry weight basis when the total nitrogen content was analyzed.
This was significantly higher than the protein content of the crude seaweed $(30.6 \% \pm 0.7 \%)$, which indicates that the $\mathrm{pH}$ shift process is efficient for concentrating proteins. Wong et $\mathrm{al}^{27}$ reported that seaweed protein extracts from $H$. charoides and $H$. japonica extracted using a method based on alkaline solubilization in combination with 2-mercaptoethanol, followed by precipitation with ammonium sulfate contained $83.1 \%$ and $85.0 \%$ protein, respectively. As mentioned previously, unlike the food-grade $\mathrm{pH}$-shift process, the use of 2-mercaptoethanol prevents the protein extracts from being food-grade. The $\mathrm{pH}$ shift process has earlier been shown to also concentrate the essential amino acids, compared to the crude seaweed (with the essential amino acids composing $38.5 \%$ and $42.4 \%$ of the total amino acids in the crude seaweed and in the protein-rich fraction, respectively). ${ }^{14}$ The $\mathrm{pH}$-shift process has been classified as Generally Recognized as Safe (GRAS) and, with use of food-grade acids and bases, there is no hindrance from using the protein extract in food. The process is already commercialized at a few places globally for application on muscle food byproducts.

Based on the TGA analysis, the ash content of the proteinrich fraction is $\sim 10 \%$ (Figure 5 ). This could be compared to

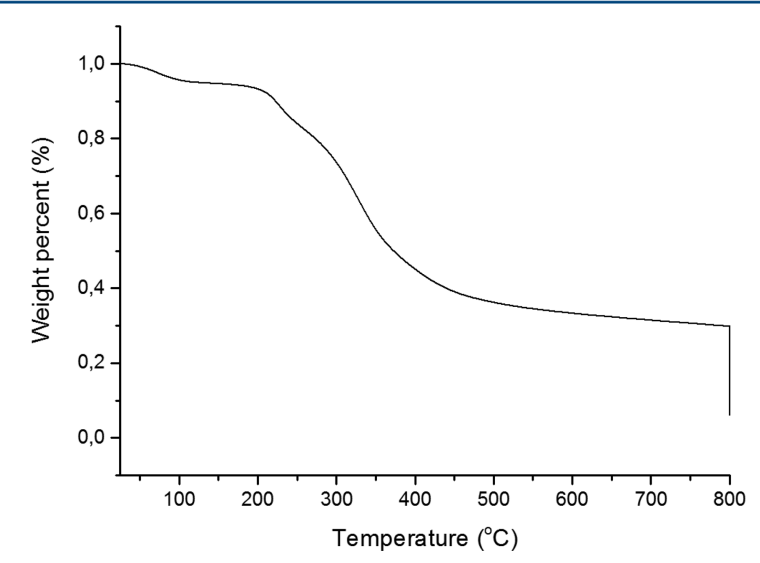

Figure 5. TGA thermogram of the protein-rich fraction.

the analysis results from classic combustion: the ash content of the $\mathrm{pH}$-shift protein fraction for Porphyra umbilicalis was then $4.7 \%$ on a dry weight basis. ${ }^{14}$ The differential weight loss data versus temperature, as measured with TGA, is available in Figure S3 in the Supporting Information.

A SEM micrograph used to analyze the morphology of the protein-rich fraction is shown in the Supporting Information (Figure S1a).

Table 4. Carbohydrate and Uronic Acid Composition, Given as the Relative Percentage of Organic Material, of the FreezeDried Porphyra umbilicalis before Fractionation, and in Recovered Samples after Different Fractionation Steps ${ }^{a}$

\begin{tabular}{|c|c|c|c|c|c|c|c|c|}
\hline & \multicolumn{8}{|c|}{ Composition (\%) } \\
\hline & Ara & Gal & Glu & Xyl & Rha & Man & GlcA & GalA \\
\hline Porphyra umbilicalis before fractionation & 1.6 & 84.0 & 1.5 & 2.4 & 1.7 & 8.8 & $b$ & $b$ \\
\hline carrageenan -rich fraction & $b$ & 100 & $b$ & $b$ & $b$ & $b$ & $b$ & $b$ \\
\hline pectin-rich fraction & 0.9 & 87.1 & 5.0 & 2.2 & 0.7 & 1.6 & 1.8 & 0.7 \\
\hline cellulose-rich fraction & $b$ & 11.0 & 89.0 & $b$ & $b$ & $b$ & $b$ & $b$ \\
\hline
\end{tabular}

${ }^{a}$ The abbreviations for the carbohydrates are as follows: Ara $\equiv$ arabinose, Gal $\equiv$ galactose, Glu $\equiv$ glucose, Xyl $\equiv$ xylose, Rha $\equiv$ rhamnose, Man $\equiv$ mannose, GlcA $\equiv$ glucuronic acid, and GalA $\equiv$ galacturonic acid. The data are given as the mean values of two replicates. ${ }^{b}$ Value is below the detection limit. 
3.4. Specific Analysis of the Carrageenan-Rich Fraction. A carrageenan-rich fraction was extracted (Figure 2, step (2)), following protein recovery. The FTIR spectrum confirms the presence of the characteristic peaks of carrageenan in the recovered fraction (Figure 6, top) and they have a strong
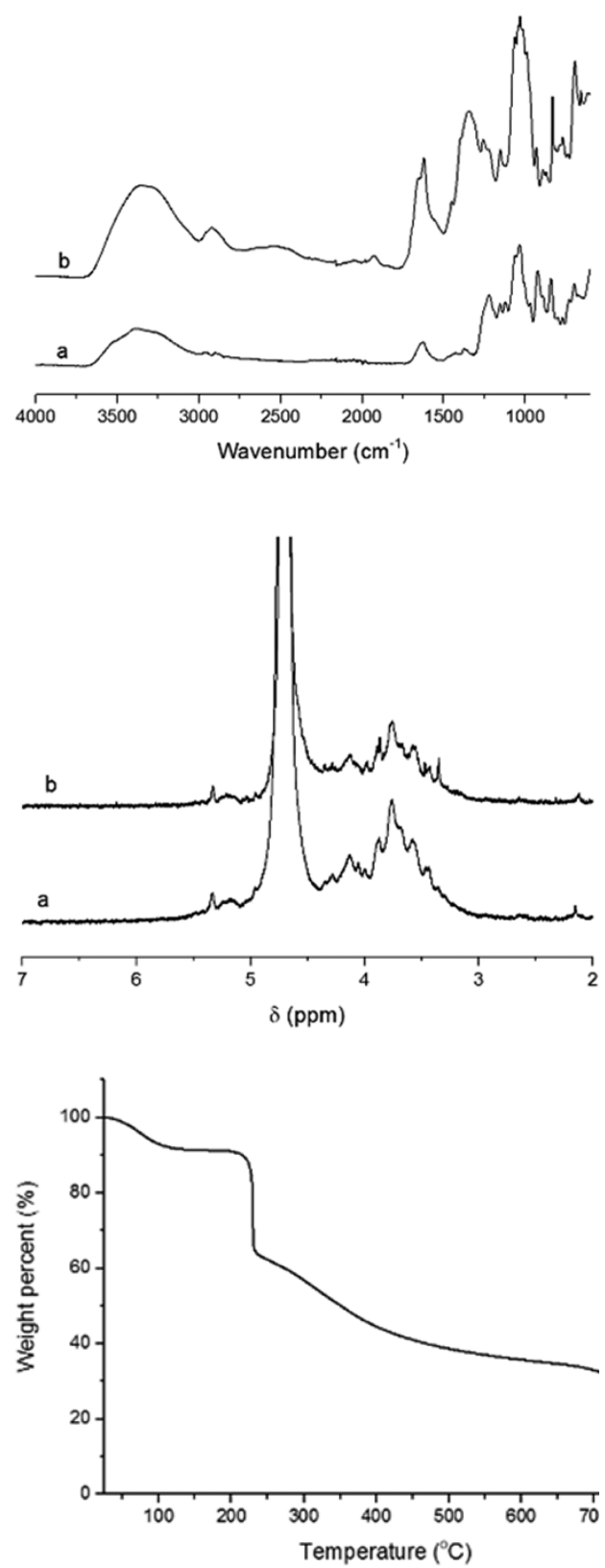

Figure 6. (Top panel) FTIR spectrum of (a) the reference carrageenan and (b) the carrageenan-rich fraction extracted from Porphyra umbilicalis. (Middle panel) ${ }^{1} \mathrm{H}$ NMR spectrum of (a) the reference carrageenan and (b) the carrageenan-rich fraction extracted from Porphyra umbilicalis. (Bottom panel) TGA thermogram for the carrageenan-enriched fraction extracted from Porphyra umbilicalis.

resemblance to the commercial carrageenan sample used as a reference. A list of the identified peaks and peak designations is available in Table S3 in the Supporting Information. The peak at $1257 \mathrm{~cm}^{-1}$ corresponds to the sulfate ester groups in carrageenan. The sharp peak at $930 \mathrm{~cm}^{-1}$ is characteristic of $l$ carrageenan and $\kappa$-carrageenan. ${ }^{28}$ The peak at $831 \mathrm{~cm}^{-1}$ is characteristic of the $\mathrm{C}-\mathrm{O}-\mathrm{SO}_{3}$ vibration in $\lambda$-carrageenan. In addition, a small peak at $806 \mathrm{~cm}^{-1}$ is observed, which indicates the presence of $l$-carrageenan. ${ }^{18}$ When comparing the FTIR spectrum of the carrageenan fraction (Figure 6, top) to the FTIR spectrum of the freeze-dried Porphyra umbilicalis before fractionation (Figure 4, left), it is clear that the former lacks a peak corresponding to $\mathrm{N}-\mathrm{H}$ bending at $\sim 1550 \mathrm{~cm}^{-1}$, which indicates that no protein is left in the carrageenan fraction (meaning the carrageenan has successfully been separated from the proteins). In addition, no peak at $\sim 1700 \mathrm{~cm}^{-1}$ was observed in the FTIR spectrum for carrageenan, which indicates that there are no $\mathrm{C}=\mathrm{O}$ groups in the carrageenan. This means that no uronic acid-and, hence, no pectin-is present in this fraction. Based on FTIR analysis, the extracted carrageenan is a mixture of $\kappa$-, $l$-, and $\lambda$-carrageenan.

The signals between 4.5 and $3.0 \mathrm{ppm}$ in the NMR spectrum (Figure 6, middle) are characteristic of the ring hydrogens of polysaccharides. The weak signals at $5.17 \mathrm{ppm}$ and $5.33 \mathrm{ppm}$ are characteristic of $\kappa$-carrageenan and $l$-carrageenan, respectively. ${ }^{29}$ No peak for $\lambda$-carrageenan was observed probably due to the low resolution caused by the high viscosity of the sample.

The SEC measurements confirmed that the extracted carrageenan fraction is indeed polymeric. A number-average molecular weight $\left(M_{\mathrm{n}}\right)$ of $715000 \mathrm{~g} / \mathrm{mol}$, a weight-average molecular weight $\left(M_{\mathrm{w}}\right)$ of $1380000 \mathrm{~g} / \mathrm{mol}$, and a dispersity $(\boxplus)$ of 1.9 were recorded. The molecular weight was quite high and, most likely, an overestimation. SEC estimates the molecular weight by measuring the hydrodynamic volume of the sample relative to a standard of known molecular weight. However, carrageenan molecules (especially $\kappa$-carrageenan) have a tendency to aggregate in solution at lower temperatures in the presence of metal ions. ${ }^{18}$ Since the SEC analysis was carried out at a rather low temperature $\left(40{ }^{\circ} \mathrm{C}\right)$ and because $\mathrm{Na}^{+}$was present in the eluent, aggregate formation was expected under these conditions. Therefore, the estimated hydrodynamic volume was probably the hydrodynamic volume of a cluster of carrageenan molecules rather than the individual chain coils. In addition, the estimated molecular weight was higher than the molecular weight of the pullulan reference sample with the highest molecular weight $(708000 \mathrm{~g} / \mathrm{mol})$ which made the calibration less reliable. Finally, the reference sample is a neutral polymer while carrageenan is an anionic polymer. Therefore, the samples were likely to have different affinities to the eluent, so their hydrodynamic volumes were not fully comparable. Still, the recovered carrageenan fraction was undoubtedly polymeric. Previous studies on carrageenan extracted from red seaweed reported a high molecular weight (400 000-2 $200000 \mathrm{~g} / \mathrm{mol}$ ) and dispersities between 2 and 4, so the results are reasonable. ${ }^{5}$

The ash content of the carrageenan-rich fraction was quantified from TGA analysis (see Table 2 and Figure 6, bottom), and the differential weight loss data versus temperature, as measured with TGA, is available in Figure S4 in the Supporting Information. The ash content is somewhat higher than that of the crude algae before fractionation. This is probably because $\mathrm{Na}^{+}$acts as a counterion in carrageenan and will remain in the solid phase, rather than being solubilized and enriched in the liquid supernatant in step (2). In addition, sodium was added to the biomass, in the form of $\mathrm{Na}_{2} \mathrm{CO}_{3}$, which acted as a mediator in the extraction step, allowing more sodium to bind to the carrageenan phase. The effect of this is observed in the results of the elemental composition analysis by SEM-EDS (Table 3), which revealed that the carrageenan-rich fraction contains a significantly higher amount of sodium than 

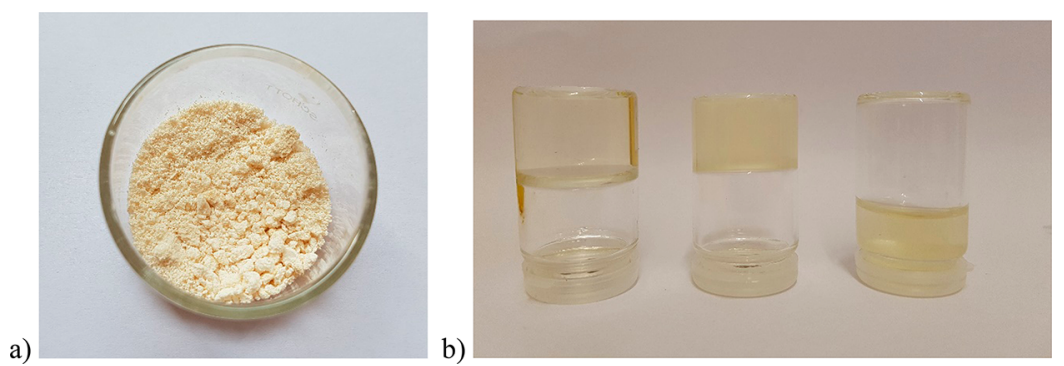

Figure 7. (a) Carrageenan-rich fraction extracted from Porphyra umbilicalis. (b) Samples from the gelling experiments: (left) commercial $\kappa$-type carrageenan mixed with $\mathrm{K}^{+}$, (middle) the carrageenan-rich fraction extracted from Porphyra umbilicalis mixed with $\mathrm{K}^{+}$, and (right) the carrageenanrich fraction extracted from Porphyra umbilicalis mixed with $\mathrm{Ca}^{2+}$.

the crude algal biomass. The carrageenan-rich fraction also contain sulfur that is indicative of a sulfated polysaccharide.

A SEM micrograph used to analyze the morphology of the carrageenan-rich fraction is shown in the Supporting Information (Figure S1b).

As discussed above, the FTIR analysis indicated that the extracted carrageenan-rich fraction is a mixture of $\kappa$-, $l$-, and $\lambda$ carrageenans. The different hybrids of carrageenan have different gelling behaviors; the $\kappa$-type forms gels in the presence of $\mathrm{K}^{+}, l$-carrageenan forms gels in the presence of $\mathrm{Ca}^{2+}$, and $\lambda$-carrageenan tends to not form gels at all under these conditions. ${ }^{9}$ To test the gelling ability of the carrageenanrich fraction extracted from Porphyra umbilicalis, aqueous solutions of the isolated and dried carrageenan-rich fraction (Figure 7a) were mixed with either $\mathrm{K}^{+}$or $\mathrm{Ca}^{2+}$ ions, heated, and then cooled to room temperature. A commercial $\kappa$-type carrageenan was used as a reference sample and treated in the same way as the extracted carrageenan-rich fraction from Porphyra umbilicalis. The commercial $\kappa$-type carrageenan readily formed a gel with $\mathrm{K}^{+}$(Figure $7 \mathrm{~b}$, left), as expected. Similarly, the extracted carrageenan-rich fraction formed a gel with $\mathrm{K}^{+}$(Figure $7 \mathrm{~b}$, middle), and no gel was formed when the extracted carrageenan-rich fraction was mixed with $\mathrm{Ca}^{2+}$ (Figure $7 b$, right). In the latter case, an opaque solution formed but it did not gel, even after an extended period of time. This indicates that the extracted carrageenan-rich fraction contains a fair amount of the $\kappa$-type carrageenan hybrid.

3.5. Specific Analysis of the Pectin-Rich Fraction. The FTIR spectra of the freeze-dried Porphyra umbilicalis biomass before fractionation and the carrageenan and pectin fractions also show peaks characteristic of polysaccharides (Figure 8, top). A list of the identified peaks and peak designations is available in Table S4 in the Supporting Information. The bands from $\mathrm{O}-\mathrm{H}, \mathrm{C}-\mathrm{H}$, and $\mathrm{C}-\mathrm{O}-\mathrm{C}$ stretching are observed along with peaks for bounded water and $\beta$-glycoside bonds. However, there are some differences between the FTIR spectra of the carrageenan fraction and the pectin fraction. No characteristic peaks for the sulfated moieties abundant in carrageenan can be observed in the FTIR spectrum of the pectin fraction, which means that there is little or no carrageenan in this fraction. In addition, a small peak is observed at $\sim 1700 \mathrm{~cm}^{-1}$ that overlaps with the peak for absorbed water at $1642 \mathrm{~cm}^{-1}$. This peak may originate from the $\mathrm{C}=\mathrm{O}$ stretching of the carboxyl group in galacturonic acid or glucuronic acid, and it is indicative of a pectic substance.

The NMR spectrum of the pectin fraction (Figure 8, middle) shows a cluster of overlapping peaks at 4.5-3.0 ppm that are characteristic of polysaccharide ring hydrogens. Studies have shown that the characteristic peaks for pectin protons appear at
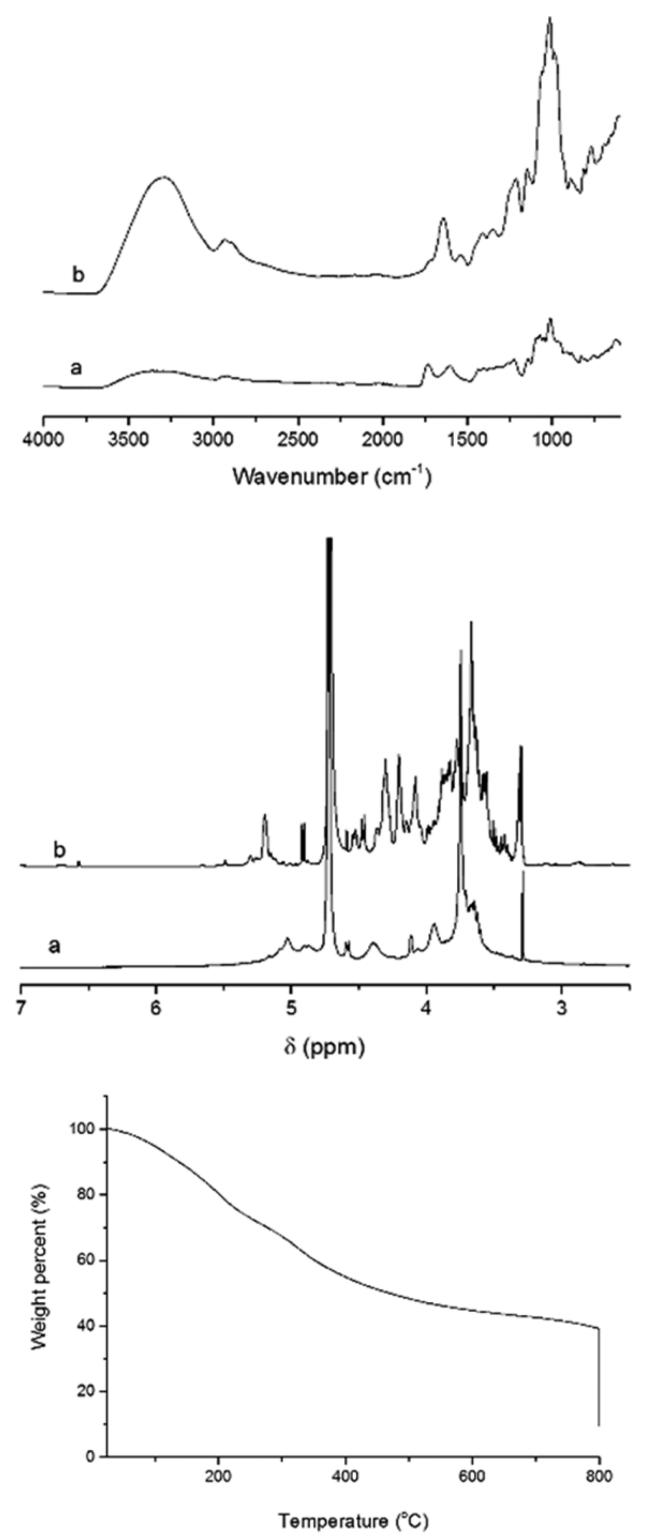

Figure 8. (Top panel) FTIR spectrum of the reference pectin (spectrum a) and pectin extracted from Porphyra umbilicalis (spectrum b). (Middle panel) ${ }^{1} \mathrm{H}$ NMR spectrum of the reference pectin (spectrum a) and pectin extracted from Porphyra umbilicalis (spectrum b). (Bottom panel) TGA curve for carrageenan extracted from Porphyra umbilicalis.

3.73, 3.80, 3.98, 4.41, 4.90, 4.95, and 5.08 ppm. ${ }^{19}$ Here, two characteristic peaks for pectin can be observed at 3.73 and 4.90 

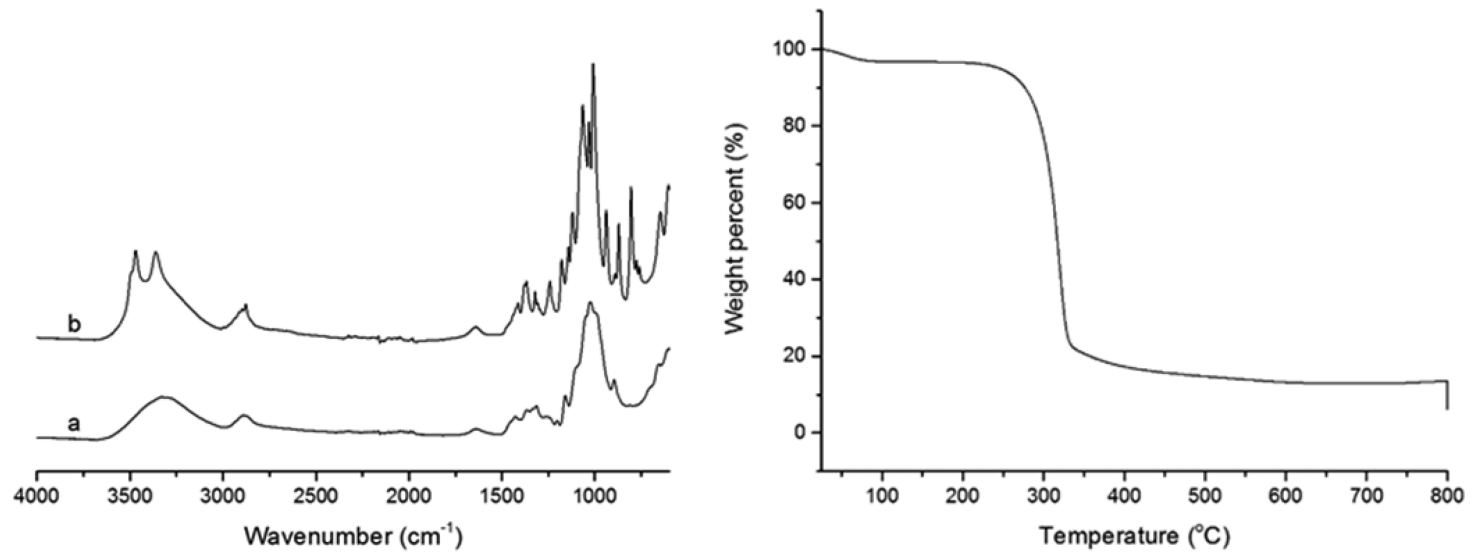

Figure 9. (Left) FTIR spectrum of the $\alpha$-cellulose reference from spruce wood (spectrum a) and the cellulose-rich fraction extracted from Porphyra umbilicalis (spectrum b). (Right) TGA curve for the cellulose-rich fraction.

ppm in the pectin-enriched fraction extracted from Porphyra umbilicalis. The pectin composition is known to vary significantly, depending on the source; therefore, the comparison to a commercial lemon pectin in Figure 8 is only valid to some extent.

The lack of sulfate bands in the FTIR spectrum was consistent with the results of the elemental analysis (Table 3); no sulfur (S) was detected in this fraction. These results indicate that the pectin-rich fraction is essentially free from carrageenan. Sodium, which is known to associate strongly with carrageenan, is less abundant in this fraction than in the Porphyra umbilicalis biomass before fractionation, and it is somewhat lower than in the carrageenan-rich fraction. The ash content remaining after TGA analysis (Figure 7, bottom) is slightly lower than the ash content of Porphyra umbilicalis before fractionation and significantly lower than the ash contents of the protein-rich and the carrageenan-rich fractions, which suggests that ions such as $\mathrm{Mg}$ and $\mathrm{Na}$ were both extracted before this stage. The differential weight loss data versus temperature, as measured with TGA, is available in Figure S5 in the Supporting Information.

An analysis of the carbohydrate composition (Table 4) revealed some differences between the crude algae and the pectin-enriched fraction. No glucuronic acid or galacturonic acid was found in the Porphyra umbilicalis sample, but small amounts were found in the pectin-rich fraction. The main reason for this behavior is probably that the pectin fraction was subjected to methanolysis and mild TFA hydrolysis, instead of conventional hydrolysis with sulfuric acid. The milder treatment resulted in a lower degree of degradation of the hydrolytically unstable uronic acids, and the uronic acids could thus be detected in the subsequent carbohydrate analysis with HPAEC-PAD. By adding the masses of the monosaccharides, we obtain $\sim 600 \mathrm{mg}$ per $1 \mathrm{~g}$ of sample, which indicates that only $\sim 60 \%$ of the total mass is pectin. In addition, the amount of galacturonic acid in the pectin fraction was very low, compared to the monosaccharide content, which is quite different from other pectin sources, such as lemon, in which galacturonic acid is the main component. The contents of the neutral sugars xylose, arabinose, and glucose in the pectin fraction were also consistent with the expected values for a pectic substance. Even though the pectin fraction is polymeric, the molecular weight is quite low, compared to the carrageenan fraction; $M_{\mathrm{n}}=5090 \mathrm{~g} / \mathrm{mol}, M_{\mathrm{w}}=11300 \mathrm{~g} / \mathrm{mol}$, and $Ð=2.2$ were recorded by SEC analysis for the pectin fractions. Given the hydrolytic instability of pectic substances, it is likely that the fraction was somewhat degraded during fractionation and that the native molecular weight is higher than the recorded values. $^{30}$

A SEM micrograph used to analyze the morphology of the pectin-rich fraction is shown in the Supporting Information (Figure S1c).

3.6. Specific Analysis of the Cellulose-Rich Fraction. Similar to the spectra for the carrageenan-and pectin-rich fractions, the FTIR spectrum of the cellulose-rich fraction (Figure 9, left) shows characteristic polysaccharide peaks, including $\mathrm{O}-\mathrm{H}, \mathrm{C}-\mathrm{H}$, and $\mathrm{C}-\mathrm{O}-\mathrm{C}$ stretching, bounded water and the $\beta$-glycoside bonds. A list of the identified peaks and peak designations is available in Table S5 in the Supporting Information. An important difference between the spectrum of the cellulose-rich fraction and the spectrum from the reference sample of cellulose is the presence of two peaks, at $931 \mathrm{~cm}^{-1}$ and $806 \mathrm{~cm}^{-1}$, that are characteristic of $\kappa$ and $l$-carrageenan, respectively. Evidently, some residual carrageenan was present, which indicates that the cellulose-rich fraction was not a pure cellulose fraction. However, the elemental analysis (Table 3) does not detect any sulfur in this fraction, and the sodium content is also much lower than that of the freeze-dried Porphyra umbilicalis biomass before fractionation; thus, the carrageenan content could not be too high. A quantification of the carbohydrate composition of the cellulose-rich fraction reveal that the glucose content is very high (89\%; see Table 4), while galactose accounts for the rest, confirming the above conclusion that some carrageenan remained in the fraction. If purified further, the algae cellulose could present a valuable component in renewable materials. Cellulose extracted from Cladophora algae have been shown to work as reinforcing additives in a plastic matrix. ${ }^{31}$ Other potential uses of algae cellulose as a material include filter materials and consistency regulators in water dispersions. ${ }^{32}$

Overall, the ash content (Table 2) of this fraction, as measured with TGA, was lower than that of the other fractions, which suggests that inorganic ions were largely co-extracted with the other biopolymers. Only calcium remained to a measurable extent in this fraction. The TGA thermogram (Figure 9, right) and the differential weight loss data versus temperature (Figure S6 in the Supporting Information) further shows that this fraction was the most thermally stable, and it had the highest onset of thermal degradation. A SEM micrograph used to analyze the morphology of the cellulose- 
rich fraction is shown in the Supporting Information (Figure S1d).

In summary, the presented sequential fractionation method allows for the recovery of several macromolecule extracts from the same biomass. With this, we hope to contribute to a more resource efficient approach with the potential of adding value to seaweed and other biomasses by utilizing several components. Consistent with the concept of biorefining (sustainable processing of biomass into a spectrum of marketable products, such as chemicals, materials, fuel, and power), a sequential process allows for the production of several valuable component fractions. The additional value and yield from the algal biomass of course require additional processing and energy consumption. Therefore, it is important not only to use green raw materials but also to develop as green and efficient processes as possible and to benchmark new processes from a lifecycle analysis perspective against conventional processes. ${ }^{33}$ Still, a process that may not be cost-effective based on one component only can be enabled if other components are also utilized and sold as valuable new materials. While vegetarian proteins are highly interesting food and feed ingredients, the polysaccharides represent new material feedstock with many opportunities for the polymer processing industry to shift from petroleum hydrocarbons to renewable resources. Regarding proteins, total protein levels in most seaweed species are too low to directly use them as protein ingredients in feed. ${ }^{34}$ Also, the though polysaccharide-rich cell wall and the abundance of polyphenols reduce the digestibility of the proteins. ${ }^{35,36}$ To be able to utilize seaweed as a protein source, it is therefore necessary to extract and concentrate the proteins, as demonstrated in this work. Furthermore, this will increase the value of the seaweed proteins. So far, there has been no use of the residual sediment from the first step in the $\mathrm{pH}$-shift process. In our biorefinery process, the sediment byproduct from this process is the raw material used for the extraction of carrageenan. Converting this and other biopolymers from Porphyra to valuable products would mean that useful renewable materials are made available to the market, and it was possible to downgrade them to solid fuel or field fertilization by composting after their service life. Another benefit with macroalgal biorefining is the possibility of recovering biomolecules that are not accessible elsewhere and that mankind cannot (at least not yet) produce synthetically. Carrageenan is a good example of such a unique component. A sequential extraction like this will minimize transportation and make more efficient use of the already-existing infrastructure. In the presented process, the yield of cellulose is small and this fraction may not be viable as a materials feedstock if the produced volume is minor. However, the yields of pectin and carrageenan are substantial. Both of these fractions can be obtained in a reasonable pure state. In addition, the polysaccharide fractions are free from heavy metals such as As, $\mathrm{Cd}$, and $\mathrm{Pb}$ that otherwise would limit the safe use of these components in materials design.

\section{CONCLUSIONS}

Fractions enriched in proteins, carrageenan, pectin, and cellulose (insoluble fraction) were successfully extracted from the red macroalgae Porphyra umbilicalis in a sequential fractionation protocol that was purposely developed to enable the recovery of multiple biomacromolecules from seaweed biomass in a biorefinery approach. The yield of protein in the protein-enriched fraction was $15.0 \%(\mathrm{w} / \mathrm{w})$, while its weight contributed to $7.5 \%$ of the initial seaweed mass. Regarding the carrageenan- and pectin-rich fractions, extraction weight yields were close to $20 \%(\mathrm{w} / \mathrm{w})$ each, and they were recovered in subsequent steps. The protein-enriched fraction contained 57\% protein. The carrageenan-rich fraction, which was extracted with an aqueous $\mathrm{Na}_{2} \mathrm{CO}_{3}$, had a very high molecular weight. ${ }^{1} \mathrm{H}$ NMR and FTIR analyses indicated that this fraction was a mixture of $\kappa$-carrageenan, $l$-carrageenan, and $\lambda$-carrageenan and was essentially free from proteins and carboxylated pectins. The carrageenan-rich fraction formed gels in aqueous solution upon the addition of $\mathrm{K}^{+}$ions. The pectin-rich fraction was isolated after the carrageenan-rich fraction was essentially free from carrageenan. The pectic substance contained galactose and uronic acid building blocks. After the final step, a cellulose-rich insoluble phase remained.

\section{ASSOCIATED CONTENT}

\section{Supporting Information}

The Supporting Information is available free of charge on the ACS Publications website at DOI: 10.1021/acs.iecr.7b03768.

SEM micrographs of the proteins and polysaccharide fractions extracted from Porphyra umbilicalis; table giving the overall composition of Porphyra umbilicalis (Table S1); FTIR peak values of Porphyra umbilicalis (Table S2), the carrageenan-rich fraction (Table S3), the pectin-rich fraction (Table S4), and the cellulose-rich fraction (Table S5); TGA curves of Porphyra umbilicalis (Figure S2), the protein-rich fraction (Figure S3), the carrageenan-rich fraction (Figure S4), the pectin-rich fraction (Figure S5), and the cellulose-rich fraction (Figure S6) PDF)

\section{AUTHOR INFORMATION}

\section{Corresponding Author}

*E-mail: edlund@kth.se.

\section{ORCID}

Ulrica Edlund: 0000-0002-1631-1781

\section{Author Contributions}

The manuscript was written through contributions of all authors. Regarding the experimental work, Hanna Harrysson and Ingrid Undeland performed the protein extraction and protein analyses. Niklas Wahlström and Ulrica Edlund performed all subsequent extractions and analyses of the carrageenan-rich, pectin-rich and cellulose-rich fractions, as well as the SEM and SEM-EDS analyses. All authors have approved the final version of the manuscript.

\section{Notes}

The authors declare no competing financial interest.

\section{ACKNOWLEDGMENTS}

The authors thank The Swedish Foundation for Strategic Research (SSF) for their financial support (Project No. RBP140045). We thank Pär Lindén, Jennie Berglund, and Nicola Giummarella at WWSC, KTH Royal Institute of Technology, for their help and support during the SEC-measurements and HPAEC-PAD analysis of the carbohydrate composition of the pectin. Finally, we thank Gunnar Cervin, Friederike Eimer, Henrik Pavia, and Göran Nylund at the Sven Lovén Center of Marine Science at Tjärnö (University of Gothenburg) for cultivating and harvesting Porphyra umbilicalis. 


\section{REFERENCES}

(1) Chung, I. K.; Oak, J. H.; Lee, J. A.; Shin, J. A.; Kim, J. K.; Park, K. S. Installing kelp forests/seaweed beds for mitigation and adaptation against global warming: Korean Project Overview. ICES J. Mar. Sci. 2013, 70, 1038-1044.

(2) Kraan, S. Mass-cultivation of carbohydrate rich macroalgae, a possible solution for sustainable biofuel production. Mitig. Adapt. Strateg. Glob. Change. 2013, 18, 27-46.

(3) Gong, J.; You, F. Optimal design and synthesis of algal biorefinery processes for biological carbon sequestration and utilization with zero direct greenhouse gas emissions: MINLP model and global optimization algorithm. Ind. Eng. Chem. Res. 2014, 53 (4), 1563-1579.

(4) McHugh, D. J. Guide to the Seaweed Industry; FAO Fisheries Technical Paper 441, 2003; Food and Agriculture Organization of the United Nations (FAO): Rome, Italy, 105 pp.

(5) Arman, M.; Qader, S. A. U. Structural analysis of kappacarrageenan isolated from Hypnea musciformis (red algae) and evaluation as an elicitor of plant defense mechanism. Carbohydr. Polym. 2012, 88, 1264-1271.

(6) Hilliou, L.; Larotonda, F. D. S.; Abreu, P.; Ramos, A. M.; Sereno, A. M.; Gonçalves, M. P. Effect of extraction parameters on the chemical structure and gel-properties of $\kappa / \imath$ carrageenan obtained from Mastocarpus stellatus. Biomol. Eng. 2006, 23, 201-208.

(7) Vázquez-Delfín, E.; Robledo, D.; Freile-Pelegrín, Y. Microwaveassisted extraction of carrageenan from Hypnea musciformis (Cystocloniaceae, Rhodophyta). J. Appl. Phycol. 2014, 26, 901-907.

(8) Popa, E. G.; Gomes, M. E.; Reis, R. L. Cell delivery systems using alginate-carrageenan hydrogel beads and fibers for regenerative medicine applications. Biomacromolecules 2011, 12 (11), 3952-3961.

(9) Wang, Q.; Rademacher, B.; Sedlmeyer, F.; Kulozik, U. Gelation behavior of aqueous solutions of different types of carrageenan investigated by low-intensity-ultrasound measurements and comparison to rheological measurements. Innovative Food Sci. Emerging Technol. 2005, 6, 465-472.

(10) Ragauskas, A. J.; Williams, C. K.; Davison, B. H.; Britovsek, G.; Cairney, J.; Eckert, C. A.; Frederick, W. J.; Hallett, J. P.; Leak, D. J.; Liotta, C. L.; Mielenz, J. R.; Murphy, R.; Templer, R.; Tschaplinski, T. The path forward for biofuels and biomaterials. Science 2006, 311, 484-489.

(11) Giuliano, A.; Cerulli, R.; Poletto, M.; Raiconi, G.; Barletta, V. Process pathways optimization for a lignocellulosic biorefinery producing levulinic acid, succinic acid, and ethanol. Ind. Eng. Chem. Res. 2016, 55 (40), 10699-10717.

(12) Silva, C.; Soliman, E.; Cameron, G.; Fabiano, L. A.; Seider, W. D.; Dunlop, E. H.; Coaldrake, A. K. Commercial-scale biodiesel production from algae. Ind. Eng. Chem. Res. 2014, 53 (13), 53115324.

(13) Vilg, J. V.; Undeland, I. pH-driven solubilization and isoelectric precipitation of proteins from the brown seaweed Saccharina latissima-effects of osmotic shock, water volume and temperature. J. Appl. Phycol. 2017, 29, 585-593.

(14) Harrysson, H.; Hayes, M.; Eimer, F.; Carlsson, N.-G.; Toth, G. B.; Undeland, I. Production of protein extracts from Swedish seaweeds Porphyra umbilicalis Kützing, Ulva lactuca Linnaeus and Saccharina latissima (Linnaeus) J. V. Lamouroux using three different methods. Submitted for publication, 2017.

(15) Fleurence, J.; Le Coeur, C.; Mabeau, S.; Maurice, M.; Landrein, A. Comparison of different extractive procedures for proteins from the edible seaweeds Ulva rigida and Ulva rotundata. J. Appl. Phycol. 1995, 7, 577-582.

(16) Joubert, Y.; Fleurence, J. Simultaneous extraction of proteins and DNA by an enzymatic treatment of the cell wall of Palmaria palmata (Rhodophyta). J. Appl. Phycol. 2008, 20, 55-61.

(17) Lee, S. J.; Yoon, B. D.; Oh, H. M. Rapid method for the determination of lipid from the green alga Botryococcus braunii. Biotechnol. Tech. 1998, 12, 553-556.

(18) Siddhanta, A. K.; Prasad, K.; Meena, R.; Prasad, G.; Mehta, G. K.; Chhatbar, M. U.; Oza, M. D.; Kumar, S.; Sanandiya, N. D. Profiling of cellulose content in Indian seaweed species. Bioresour. Technol. 2009, 100, 6669-6673.

(19) Garna, H.; Mabon, N.; Nott, K.; Wathelet, B.; Paquot, M. Kinetic of the hydrolysis of pectin galacturonic acid chains and quantification by ionic chromatography. Food Chem. 2006, 96, 477484.

(20) Angell, A. R.; Mata, L.; de Nys, R.; Paul, N. A. The protein content of seaweeds: A universal nitrogen-to-protein conversion factor of five. J. Appl. Phycol. 2016, 28, 511-524.

(21) Wong, K. H.; Cheung, P. C. K. Nutritional evaluation of some subtropical red and green seaweeds. Part II. In vitro protein digestibility and amino acid profiles of protein concentrates. Food Chem. 2001, 72, 11-17.

(22) Aylward, G.; Findlay, T. SI Chemical Data, 5th Edition; John Wiley \& Sons: Australia, 2008 (ISBN No. 0-470-81638-4).

(23) Smith, J. L.; Summers, G.; Wong, R. Nutrient and heavy metal content of edible seaweeds in New Zealand. N. Z. J. Crop Hortic. Sci. 2010, 38, 19-28.

(24) Rupérez, P. Mineral content of edible marine seaweeds. Food Chem. 2002, 79, 23-26.

(25) Cian, R. E.; Fajardo, M. A.; Alaiz, M.; Vioque, J.; González, R. J.; Drago, S. R. Chemical composition, nutritional and antioxidant properties of the red edible seaweed Porphyra columbina. Int. J. Food Sci. Nutr. 2014, 65, 299-305.

(26) Maehre, H. K.; Malde, M. K.; Eilertsen, K.-E.; Elvevoll, E. O. Characterization of protein, lipid and mineral contents in common Norwegian seaweeds and evaluation of their potential as food and feed. J. Sci. Food Agric. 2014, 94, 3281-3290.

(27) Wong, K. H.; Cheung, P. C. K. Nutritional evaluation of some subtropical red and green seaweeds. Part II. In vitro protein digestibility and amino acid profiles of protein concentrates. Food Chem. 2001, 72, 11-17.

(28) Pereira, L.; Amado, A. M.; Critchley, A. T.; van de Velde, F.; Ribeiro-Claro, P. J. A. Identification of selected seaweed polysaccharides (phycocolloids) by vibrational spectroscopy (FTIR-ATR and FT-Raman). Food Hydrocolloids 2009, 23, 1903-1909.

(29) Tojo, E.; Prado, J. A simple ${ }^{1} \mathrm{H}$ NMR method for quantification of carrageenans in blends. Carbohydr. Polym. 2003, 53, 325-329.

(30) Guichard, E.; Issanchou, S.; Descourvieres, A.; Etievant, P. Pectin Concentration, Molecular Weight and Degree of Esterification: Influence on Volatile Composition and Sensory Characteristics of Strawberry Jam. J. Food Sci. 1991, 56, 1621-1627.

(31) Johnson, M.; Shivkumar, S. Filamentous green algae additions to isocyanate based foams. J. Appl. Polym. Sci. 2004, 93, 2469-2477.

(32) Mihranyan, A. Cellulose from Cladophorales green algae: From environmental problem to high-tech composite materials. J. Appl. Polym. Sci. 2011, 119, 2449-2460.

(33) Sterner, M.; Ribeiro, M. S.; Gröndahl, F.; Edlund, U. Cyclic fractionation process for Saccharina latissima using aqueous chelator and ion exchange resin. J. Appl. Phycol. 2017, 29, 3175.

(34) Maehre, H. K.; Malde, M. K.; Eilertsen, K.-E.; Elvevoll, E. O. Characterization of protein, lipid and mineral contents in common Norwegian seaweeds and evaluation of their potential as food and feed. J. Sci. Food Agric. 2014, 94, 3281-3290.

(35) Joubert, Y.; Fleurence, J. Simultaneous extraction of proteins and DNA by an enzymatic treatment of the cell wall of Palmaria palmata (Rhodophyta). J. Appl. Phycol. 2008, 20, 55-61.

(36) Harnedy, P. A.; FitzGerald, R. J. Extraction of protein from the macroalga Palmaria palmata. LWT -. Food Sci. Technol. 2013, 51, 375382. 